\title{
Association of lung consolidation with clinical prognosis in children with Mycoplasma pneumoniae pneumonia: a retrospective study
}

\section{Caiting Chu}

Shanghai Jiaotong University School of Medicine Xinhua Hospital

\section{Lijun Wang}

Shanghai Jiaotong University School of Medicine Xinhua Hospital

Huajun Li

Shanghai Jiaotong University School of Medicine Xinhua Hospital

\section{Shanshan Xu}

Shanghai Jiaotong University School of Medicine Xinhua Hospital

\section{Liya Zhang}

Shanghai Jiaotong University School of Medicine Xinhua Hospital

\section{Quanhua Liu}

Shanghai Jiaotong University School of Medicine Xinhua Hospital

\section{Xi Zhang}

Shanghai Jiaotong University School of Medicine Xinhua Hospital

\section{Weixi Zhang}

Shanghai Jiaotong University School of Medicine Xinhua Hospital

\section{Wenhua Li}

Shanghai Jiaotong University School of Medicine Xinhua Hospital

Lisu Huang ( $\nabla$ huanglisu@xinhuamed.com.cn)

Shanghai Jiaotong University School of Medicine Xinhua Hospital https://orcid.org/0000-0001-81937353

\section{Research}

Keywords: Mycoplasma pneumoniae pneumonia, children, computed tomography, lobar consolidation, clinical course

Posted Date: May 5th, 2021

DOI: https://doi.org/10.21203/rs.3.rs-486538/v1 
License: (c) (i) This work is licensed under a Creative Commons Attribution 4.0 International License. Read Full License 


\section{Abstract \\ Objectives}

Lung consolidation is common in patients with Mycoplasma pneumoniae pneumonia (MPP). In this study, we aimed to investigate whether this lung lesion associated with the severity and prognosis of MPP.

\section{Methods}

Clinical experts reassessed and collected the clinical characteristics, imaging features, and laboratory examination of 752 hospitalized children with MPP who received low-dose computerized tomography (CT) examination between August 2014 and July 2019. We evaluated the impact of lobar consolidation on the fever duration and length of hospital stay using Kaplan-Meier analysis and COX model. The relationship between lobar consolidation and inflammatory markers was also determined, as well as hospital charges.

\section{Results}

Among the 752 patients included, 90.3\% (679/752) presented lung consolidation, 25.1\% (189/752) with 2 or more lobar consolidation, and 16.2\% (122/752) patients developed severe MPP (SMPP). Beyond pleural effusion, lobar consolidation had the highest risk of SMPP among low-dose CT imaging-based evidence. Compared with 0 and 1 lobar consolidation, 2 lobes, 3 lobes, and 4 lobes were associated with a 1-fold, 3.1-fold, and 7.5-fold increased risk of SMPP (OR 2.0 [95\% Cl 1.3-3.2], OR 4.1 [95\% Cl 2.0-8.5], OR 8.5 [95\% $\mathrm{Cl} 2.2-32.6])$. The length of stay and fever duration were prolonged correspondingly with increase of number of lobar consolidation, as were hospital charges.

\section{Conclusion}

Lobar consolidation is a stable and reliable CT feature for assessing of severity of illness and clinical prognosis for children with MPP.

\section{Background}

Mycoplasma pneumoniae pneumonia (MPP), one of the most common respiratory tract infections in children, accounts for $8-37.5 \%$ of all community-acquired pneumonia (CAP) cases [1, 2]. Although M. pneumoniae infections generally are mild and self-limiting, patients of study has shown about $12 \%$ of hospitalized children with MPP required intensive care[3]. Some patients with M. pneumoniae may develop extrapulmonary manifestations, such as encephalitis, arthritis, and pericarditis, presenting with a severe clinical course [4,5]. Hence, early and accurate assessment of the clinical course of MPP is crucial 
for patients and clinicians. Usually, chest radiography (CR) is the first-line investigation for patients with suspected CAP. However, it is non-specific for MPP [6-8]. CR fails to demonstrate the details and distribution of lesions, while computed tomography (CT) can clearly show interstitial abnormalities and lobular distribution, such as bronchial wall thickening and reticulonodular or centrilobular nodules, which are common features in patients with MPP $[9,10]$. Thus, chest CT is a favourable method for assessing radiological features in cases with MPP, and it can be applied safely in children through reasonable indication and adjustment of scan parameters, such as low-dose CT. Consolidation is more frequent in MPP than in other community-acquired pneumonia on CR, accounting for $33-79 \%$ of the cases $[10,11]$. However, the association between lobar consolidation and the severity and prognosis of MPP is unclear. To our knowledge, only a few articles are presently available that describe the imaging findings of MPP on CR or chest CT, which primarily consists of large-area or multi-lobar consolidation [12]. The quantitative correlation analysis between consolidation features and the clinical course or prognosis is under-investigated.

Therefore, we aimed to verify consolidation confirmed by low-dose chest CT, as a critical feature with clinical significance in a large sample of patients with MPP; quantitatively evaluate the association between consolidation and the clinical course; thus, ensure that patients receive timely and reasonable treatment.

\section{Methods}

\section{Patients}

In the period between February 2016 and July 2019, 917 out of 5112 hospitalized children with CAP were diagnosed with MPP in Xinhua Hospital, affiliated to Shanghai Jiao Tong University School of Medicine. MPP was diagnosed based on the following conditions: (i) fever, cough, or auscultatory findings and a pulmonary infiltrate visible on chest imaging; and (ii) $M$. pneumoniae DNA detected in nasopharyngeal secretions by polymerase chain reaction or $\geq 4$-fold changes in $M$. pneumoniae IgM and IgG antibody titre between paired acute and convalescent sera, according to the Infectious Diseases Society of America guidelines of $2018[13,14]$. Patients with mixed infection, immunodeficiency, and congenital diseases were excluded. Finally, 752 patients with MPP who underwent low-dose CT were included in the study. The workflow is displayed in Figure 1. This retrospective study was approved by the Institutional Ethics Committee of our hospital, and informed consent was obtained.

\section{General, clinical, and laboratory characteristics}

General information, clinical symptoms, and laboratory examination were re-evaluated by infectious specialists who reviewed the clinical records of patients enrolled in this study: general characteristics, including sex and age; clinical symptoms, including duration of fever prior to and after admission (days), total duration of fever (days), length of stay (days), rash, neurological symptoms, encephalitis, hypoxemia, treatment in intensive care unit, and death; and laboratory indices such as lactate 
dehydrogenase (LDH) and interleukin 2-receptor (IL-2R), as well as C-reactive protein (CRP) level at the time of admission.

\section{Image analyses}

Low-dose CT examinations were performed using 64-detector row CT (Brilliance iCT, Philips) [15]. Evaluation of CT features, including consolidation, bronchial wall thickening, nodules, ground grass attenuation, interstitial reticulation opacities, bilateral pneumonia, atelectasis, lymphadenopathy, and pleural effusion, were guided by expert consensus from a Delphi study on image assessment of patients with MPP $[9,7,8,10,16]$ (Figure 2). Based on the related features of consolidation, all patients were further evaluated for the following features: the number of lobe consolidation, location of lobar consolidation (upper, middle, or lower right lung lobe; upper or lower left lung lobe), and the occurrence of consolidation without air bronchograms. Two chest radiologists independently assessed the CT images of each patient. Consensuses reached by both of them were as the final appraisal reports. Disagreements were resolved by consulting a third chest radiologist with 12 years of experience.

Each patient's medical history was re-evaluated by an adjudication experts committee including paediatricians, radiologists, and infection specialists. Severe pneumonia was assessed according to the guidelines by the Paediatric Infectious Diseases Society and Infectious Diseases Society of America on the management of CAP in infants and children older than three months [17]. Refractory pneumonia was defined as prolonged fever, worsening of clinical symptoms, emergence of extrapulmonary complications, and deteriorating radiological findings, despite administration of appropriate macrolide therapy $\geq 7$ days [18].

\section{Statistical analyses}

Categorical variables are expressed with $\mathrm{n}(\%)$ and continuous variables are presented as median (interquartile range [IQR]). Differences in clinical and radiological variables in children with MPP were assessed using Chi-squared test for Categorical variables and $t$ test or Mann-Whitney $U$ test for continuous variables. Spearman's method was used to analyse the association between lobar consolidation and laboratory indices. Logistic regression analyses were then performed to assess the correlation between lobar consolidation and the clinical course. The association between lobar consolidation category and prognosis, including fever duration after admission and length of hospital stay, was assessed using Kaplan-Meier estimates, and using Cox proportional-hazard models to calculate hazard ratios (HRs) with $95 \%$ confidence. $P<0.05$ indicated a statistically significant difference. Statistical analyses used R (https://www.R-project.org, R foundation for Statistical Computing, Vienna, Austria).

\section{Results}

Of the 5112 patients with a diagnosis of CAP during the study time frame, 752 patients met eligibility criteria and were included in the study cohort (Figure 1), 122 of 752 patients $(16.2 \%$ ) had SMPP (Table 1). 
Most patients were pre-school and school-aged children. Patients with SMPP were more likely to have neurological symptoms, encephalitis, hypoxemia, refractory pneumonia and receive treatment in intensive care unit, and they had higher LDH, IL-2R, and CRP levels. Furthermore, patients with SMPP also tended to have longer median fever duration after admission, total fever duration, length of hospital stay (median 3.0 [IQR 2.0-4.0], 9.0 [IQR 7.0-12.0], and 9.0 [IQR 7.0-12.0] respectively) than those without SMPP.

Consolidation was present in $90.3 \%$ (679/752) of children with MPP, and this rate was the second only to that of bronchial wall thickening (93.2\%) (Table 2). The proportions for one, two, three, and four lobar consolidations were $65.1 \%, 19.3 \%, 4.7 \%$, and $1.2 \%$, respectively. Pleural effusion and atelectasis were observed in $15.8 \%$ and $9.7 \%$ of patients with MPP. Compared with zero and one lobar consolidations, two, three, and four lobes were associated with a 1-fold, 3.1-fold, and 7.5-fold increased risk of SMPP (OR 2.0 [95\% Cl 1.3-3.2], OR 4.1 [95\% Cl 2.0-8.5], OR 8.5 [95\% Cl 2.2-32.6]). The presence of consolidation without air bronchogram was an independent risk factor for SMPP (OR 3.7 [95\% $\mathrm{Cl} 2.3-6.0]$ ). Patients with atelectasis had a significantly higher rate of SMPP (OR 3.9 [95\% $\mathrm{Cl} 2.3-6.6])$, compared with those without. The presence of lymphadenopathy was associated with SMPP (OR 1.6 [95\% $\mathrm{Cl} 1.1-2.4]$ ).

The consolidation rates were $86.6 \%, 92.6 \%, 90.2 \%, 88.5 \%$ in patients with fever durations of $\leq 3$ days, 3-6 days, $6-9$ days and $>9$ days before admission. There was little change in the proportions of the lobar consolidation subclasses over the duration of fever prior to admission (Figure 3). Levels of inflammatory markers, such as LDH, IL-2R, and CRP, consistently rose with lobar consolidation class (Figure 4).

In the Kaplan-Meier analysis (Figure 5), the risk of fever duration significantly increased with increasing lobar consolidation $(P=0.0025)$, as well as the length of stay $(P<0.0001)$. The more of consolidation lobar were associated with longer hospital length of stay, with the longest time observed for 4 lobar consolidation (HR 0.17 [95\% Cl 0.08-0.33]), followed by 3 lobar consolidation (HR 0.31 [95\% Cl $0.21-$ 0.47]), then 2 lobar consolidation (HR 0.36 [95\% $\mathrm{Cl} 0.21-0.47]$ ) and 1 lobar consolidation (HR 0.42 [95\% $\mathrm{Cl}$ 0.33-0.54]) (Table 3). Similarly, the same trends were observed for the time to defervescence. An increasing number of lobar consolidations leads to a gradual increase in costs, including hospital charges, laboratory tests, imaging costs, and medications (Table 4).

\section{Discussion}

In our large sample study, consolidation was a stable and reliable feature in assessing disease severity and prognosis in patients with MPP. Lobar consolidation was independently associated with a higher risk of SMPP, longer fever duration and length of stay, and higher costs. These results demonstrated that an increased number of lobar consolidations could predict the severity of MPP and significantly enhance the accuracy of clinical outcome prediction in patients with MPP at an early stage.

Radiographic manifestations of MPP vary, including bronchial wall thickening, reticulonodular, segmental and lobar consolidations, atelectasis, hilar lymphadenopathy, and pleural effusion. Of these, consolidation as a CT feature presents a homogeneous increase in lung parenchymal attenuation that obscures the margins of vessels and airway walls [12]. In this study, consolidation was the second most 
common imaging feature and had good stability in evaluating the MPP course. The incidence of consolidation was up to $86.6 \%$ in patients with duration of fever $\leq 3$ days, and $88.5 \%$ for duration of fever $>9$ days. In other words, the rate of consolidation was quite high in the early stages of infection and did not increase significantly with an increase of fever duration before admission, which may be relevant to type $\otimes$ hypersensitivity. Furthermore, we found that an increased number of lobar consolidations was associated with higher odds of SMPP. As a previous literature has reported, patients with consolidations were more likely to have hypoxia, tachypnoea, tachycardia, and extrapulmonary manifestations, which indicate severe pneumonia in children, than those without consolidation on CR [12]. However, to our knowledge, no study has investigated the association between the number of lobar consolidations and SMPP. This is the first study to achieve a quantitative evaluation of consolidation, which is superior to the previous vague assessments of large-area and multilobe consolidations.

Inflammatory cytokines were involved in the immunopathogenesis of Mycoplasma pneumoniae infection $[14,19]$. In our study, we found a positive correlation between lobar consolidation and LDH, IL-2R, and CRP levels in children with MPP, which is consistent with the findings of previous studies [12,14]. Mycoplasma pneumoniae attach to the ciliated epithelial cells on the respiratory tract through the P1 protein, exerting cytotoxicity by expression of community-acquired respiratory distress syndrome and production of hydrogen peroxide, then activating host immunity, including macrophages, mast cells, neutrophils, and natural killer cells, as well as $T$ and B lymphocytes and humoral immune responses [20]. Cell-mediated immunological responses play an important role in the development of MPP. In SMPP, the immune response is exaggerated, and interleukin levels are elevated, resulting in diffuse alveolar damage with fibrinous exudates within the alveolar lumens histopathologically, which was correlated with consolidation on CT [21].

The association of multilobar involvement with prognosis has been previously investigated in some studies [12, 22, 23]. Patients with more lobar consolidations experienced longer fever duration, length of stay and higher costs, which are consistent with the results of this study. Some previous studies suggested that prolonged fever duration was associated with MP macrolide resistance [24,25]. We investigated the presence of macrolide-resistant genes through convenience sampling and found that almost MP were shown to have an A-to-G transition mutation at position 2063 in the 23S rRNA genes. Meanwhile, one study revealed that the presence of homogeneous lobar consolidation was responsible for prolonged fever $\geq 7$ days after the initiation of macrolides regardless of macrolide resistance. Hence, quantitative analysis of consolidation can be more accurate in predicting the clinical course of MPP and guide rational clinical medication, with major clinical significance.

Clinicians are cautious about using CT in children because of the problem of radiation dose. First, we used a low-dose CT assessment of MPP in this study. According to scans parameters, when patients weigh $<20 \mathrm{~kg}$, the patient absorbs about 0.4-0.8 millisieverts $(\mathrm{mSv})$ of radiation, equivalent to the dose of 4-8 chest radiographs, and when patients weigh $20 \mathrm{~kg}$ to $60 \mathrm{~kg}$, the patient absorbs about 0.7-1.6 $\mathrm{mSv}$, equal to the dose of 7-16 chest radiographs [26]. Therefore, low-dose CT scans ensure safe radiation doses in children. Second, in contrast to the $33-79 \%$ incidence of consolidation currently 
reported $[10,11]$, our results showed that the proportion of patients with consolidation was up to $90.3 \%$, which is attributed to the superiority of CT over X-ray for demonstrating lesion patterns and lung anatomy [7]. Consolidation of a large area or an entire lobe can be clearly observed on CR and CT, while patchy consolidation indicative of bronchopneumonia on CT may manifest as a non-consolidative feature on CR. Additionally, we performed quantitative evaluation of consolidation. It was evident that the quantification of consolidation by CR was not achievable. Finally, low-dose CT is recommended for assessment when patients fail to respond to treatment, had severe complications suggested by $\mathrm{CR}$, or when there is a need to exclude HIV infection and tuberculosis [15]. CT examination is an important and indispensable method. Thus, using low-dose CT can not only ensure safety but also improve the validity of assessment. Low-dose CT is recommended for children with MPP with poor efficacy or requiring differential diagnoses.

Our study has some limitations. First, this study was conducted retrospectively, and therefore analysis was limited to the patient's available medical records. Second, we are unable to obtain the patients' lung pathological specimens, as a result, the correlation analysis between imaging and pathology could not be performed. Considering the repeatability and operability of the study, CT is a non-invasive examination that can best reflect the actual pathological condition. Third, as the present study was performed at a tertiary hospital, patients may present with more severe diseases than are usually admitted in primary or secondary hospitals; however, the presented associations among evaluated variables are still present and convincing.

\section{Conclusions}

Our findings showed that consolidation is a stable and reliable CT feature for evaluating MPP. Quantitative analysis of lobar consolidation can comprehensively and accurately assess and predict the clinical course of MPP. Low-dose CT examination is recommended for complex and severe hospitalized children with MPP.

\section{Abbreviations}

MPP Mycoplasma pneumoniae pneumonia; CT computed tomography; CR chest radiography; CAP community-acquired pneumonia; SMPP severe MPP; LDH lactate dehydrogenase; IL-2R interleukin 2receptor (IL-2R), CRP C-reactive protein; IQR interquartile range;

\section{Declarations}

\section{Ethics approval and consent to participate}

This retrospective study was approved by the Institutional Ethics Committee of our hospital, and informed consent was obtained from the participants. 
All the authors consent to the publication of this manuscript.

\section{Availability of data and materials}

The data and any material can be shared.

\section{Competing interests}

The authors declare that they have no competing interests.

\section{Funding}

This investigation was supported by the National Natural Science Foundation of China (No. 81530086 and No. 81874265), Shanghai Natural Science Foundation of China (No. 2017YQ033), Shanghai Talent Development Foundation (No. 2018003), Shanghai Municipal Health System Talents Program and Medical (No.2017YQ033), and Industrial Collaborated Research Foundation of Shanghai Jiao Tong University (YG2017MS75).

\section{Authors' contributions}

CC and LW designed the study and undertook most of the work, they should be regarded as co-first author. HL, SX, LZ, QL, XZ, WZ, WL and LH participated in data collection and analysis. All authors have contributed to the last version of the manuscript. The authors read and approved the final manuscript.

\section{Acknowledgements}

We thank all participants and staff of this study and the physicians at Xinhua Hospital affiliated with the Shanghai Jiao Tong University School of Medicine.

\section{Authors' information}

aDepartment of Radiology, Xinhua Hospital, Shanghai Jiao Tong University School of Medicine, Shanghai 200092, China. ${ }^{b}$ Department of Infectious Diseases, Xinhua Children's Hospital, Xinhua Hospital, Shanghai Jiao Tong University School of Medicine, Shanghai 20092, China. 'Department of Pediatric Respiration, Xinhua Hospital, Shanghai Jiao Tong University School of Medicine, Shanghai 200092, China.

${ }^{d}$ Clinical Research Unit, Xinhua Hospital, Shanghai Jiao Tong University School of Medicine, Shanghai, 200092, China. ${ }^{\mathrm{e} T h e}$ Second Affiliated Hospital and Yuying Children's Hospital of Wenzhou Medical University,China Department of Pediatric Allergy and Immunology, Wenzhou, Zhejiang, 325200, China. fDepartment of Radiology, Xinhua Hospital affiliated to Shanghai Jiao Tong University School of Medicine, Chongming Branch, Shanghai 202150, China.

\section{References}


1. Jain S, Williams DJ, Arnold SR, Ampofo K, Bramley AM, Reed C et al. Community-acquired pneumonia requiring hospitalization among U.S. children. N Engl J Med. 2015;372(9):835-45. doi:10.1056/NEJMoa1405870.

2. Gao LW, Yin J, Hu YH, Liu XY, Feng XL, He JX et al. The epidemiology of paediatric Mycoplasma pneumoniae pneumonia in North China: 2006 to 2016. Epidemiol Infect. 2019;147:e192. doi:10.1017/S0950268819000839.

3. Kutty PK, Jain S, Taylor TH, Bramley AM, Diaz MH, Ampofo K et al. Mycoplasma pneumoniae Among Children Hospitalized With Community-acquired Pneumonia. Clin Infect Dis. 2019;68(1):5-12. doi:10.1093/cid/ciy419.

4. Socan M, Ravnik I, Bencina D, Dovc P, Zakotnik B, Jazbec J. Neurological symptoms in patients whose cerebrospinal fluid is culture- and/or polymerase chain reaction-positive for Mycoplasma pneumoniae. Clin Infect Dis. 2001;32(2):E31-5. doi:10.1086/318446.

5. Moynihan KM, Barlow A, Nourse C, Heney C, Schlebusch S, Schlapbach LJ. Severe Mycoplasma Pneumoniae Infection in Children Admitted to Pediatric Intensive Care. Pediatr Infect Dis J. 2018;37(12):e336-e8. doi:10.1097/INF.0000000000002029.

6. Cameron D, Borthwick R, Philp T. The radiographic patterns of acute mycoplasma pneumonitis. Clinical radiology. 1977;28(2):173-80. doi:10.1016/s0009-9260(77)80097-4.

7. Reittner P, Müller NL, Heyneman L, Johkoh T, Park JS, Lee KS et al. Mycoplasma pneumoniae pneumonia: radiographic and high-resolution CT features in 28 patients. AJR Am J Roentgenol. 2000;174(1):37-41. doi:10.2214/ajr.174.1.1740037.

8. Gong L, Zhang CL, Zhen Q. Analysis of clinical value of CT in the diagnosis of pediatric pneumonia and mycoplasma pneumonia. Exp Ther Med. 2016;11(4):1271-4. doi:10.3892/etm.2016.3073.

9. Lee I, Kim TS, Yoon HK. Mycoplasma pneumoniae pneumonia: CT features in 16 patients. Eur Radiol. 2006;16(3):719-25. doi:10.1007/s00330-005-0026-z.

10. John SD, Ramanathan J, Swischuk LE. Spectrum of clinical and radiographic findings in pediatric mycoplasma pneumonia. Radiographics.2001;21(1):121-

31.doi:10.1148/radiographics.21.1.g01ja10121.

11. Gückel C, Benz-Bohm G, Widemann B. Mycoplasmal pneumonias in childhood. Roentgen features, differential diagnosis and review of literature. Pediatr Radiol. 1989;19(8):499-503. doi:10.1007/bf02389556.

12. Cho YJ, Han MS, Kim WS, Choi EH, Choi YH, Yun KW et al. Correlation between chest radiographic findings and clinical features in hospitalized children with Mycoplasma pneumoniae pneumonia. PLoS One. 2019;14(8):e0219463. doi:10.1371/journal.pone.0219463.

13. Miller JM, Binnicker MJ, Campbell S, Carroll KC, Chapin KC, Gilligan PH et al. A Guide to Utilization of the Microbiology Laboratory for Diagnosis of Infectious Diseases: 2018 Update by the Infectious Diseases Society of America and the American Society for Microbiology. Clin Infect Dis. 2018;67(6):e1-e94. doi:10.1093/cid/ciy381. 
14. Xu XF, Li XJ, Liu JL, Wu L, Chen ZM. Serum cytokine profile contributes to discriminating M. pneumoniae pneumonia in children. Cytokine. 2016;86:73-8. doi:10.1016/j.cyto.2016.07.018.

15. Andronikou S, Goussard P, Sorantin E. Computed tomography in children with community-acquired pneumonia. Pediatr Radiol. 2017;47(11):1431-40. doi:10.1007/s00247-017-3891-0.

16. Miyashita N, Sugiu T, Kawai Y, Oda K, Yamaguchi T, Ouchi K et al. Radiographic features of Mycoplasma pneumoniae pneumonia: differential diagnosis and performance timing. BMC Med Imaging. 2009;9:7. doi:10.1186/1471-2342-9-7.

17. Bradley JS, Byington CL, Shah SS, Alverson B, Carter ER, Harrison C et al. The management of community-acquired pneumonia in infants and children older than 3 months of age: clinical practice guidelines by the Pediatric Infectious Diseases Society and the Infectious Diseases Society of America. Clin Infect Dis. 2011;53(7):e25-76. doi:10.1093/cid/cir531.

18. Tamura A, Matsubara K, Tanaka T, Nigami H, Yura K, Fukaya T. Methylprednisolone pulse therapy for refractory Mycoplasma pneumoniae pneumonia in children. J Infect. 2008;57(3):223-8. doi:10.1016/j.jinf.2008.06.012..

19. Chaudhry R, Ghosh A, Chandolia A. Pathogenesis of Mycoplasma pneumoniae: An update. Indian J Med Microbiol. 2016;34(1):7-16. doi:10.4103/0255-0857.174112.

20. Waites KB, Xiao L, Liu Y, Balish MF, Atkinson TP. Mycoplasma pneumoniae from the Respiratory Tract and Beyond. Clin Microbiol Rev. 2017;30(3):747-809. doi:10.1128/cmr.00114-16..

21. Tanaka H. Correlation between Radiological and Pathological Findings in Patients with Mycoplasma pneumoniae Pneumonia. Frontiers in Microbiology. 2016;7. doi:10.3389/fmicb.2016.00695.

22. Guo Q, Li HY, Zhou YP, Li M, Chen XK, Peng HL et al. Associations of radiological features in Mycoplasma pneumoniae pneumonia. Arch Med Sci. 2014;10(4):725-32.

doi:10.5114/aoms.2014.44863

23. Yoon IA, Hong KB, Lee HJ, Yun KW, Park JY, Choi YH et al. Radiologic findings as a determinant and no effect of macrolide resistance on clinical course of Mycoplasma pneumoniae pneumonia. BMC Infect Dis. 2017;17(1):402. doi:10.1186/s12879-017-2500-z.

24. Suzuki S, Yamazaki T, Narita M, Okazaki N, Suzuki I, Andoh T et al. Clinical evaluation of macrolideresistant Mycoplasma pneumoniae. Antimicrob Agents Chemother. 2006;50(2):709-12. doi:10.1128/AAC.50.2.709-712.2006.

25. Matsubara K, Morozumi M, Okada T, Matsushima T, Komiyama O, Shoji M et al. A comparative clinical study of macrolide-sensitive and macrolide-resistant Mycoplasma pneumoniae infections in pediatric patients. J Infect Chemother. 2009;15(6):380-3. doi:10.1007/s10156-009-0715-7.

26. Nievelstein RA, van Dam IM, van der Molen AJ. Multidetector CT in children: current concepts and dose reduction strategies. Pediatr Radiol. 2010;40(8):1324-44. doi:10.1007/s00247-010-1714-7.

\section{Tables}


Table 1. Characteristics of children with Mycoplasma pneumoniae pneumonia stratified by severe Mycoplasma pneumoniae pneumonia (SMPP) $(n=752)$.

\begin{tabular}{|c|c|c|c|}
\hline Variables & $\begin{array}{l}\text { Non-SMPP } \\
(\mathrm{n}=630)\end{array}$ & $\begin{array}{l}\text { SMPP } \\
(n=122)\end{array}$ & $P$-value \\
\hline \multicolumn{4}{|l|}{ General characteristics } \\
\hline Male & $298(47.3)$ & $56(45.9)$ & 0.78 \\
\hline Age, years & $5.0(3.0-7.0)$ & $6.0(4.0-7.0)$ & 0.07 \\
\hline \multicolumn{4}{|l|}{ Clinical signs } \\
\hline Duration of fever prior admission, days & $6.0(5.0-8.0)$ & $7.0(5.0-8.0)$ & 0.82 \\
\hline Rash & $2(0.3)$ & $0(0.0)$ & 0.53 \\
\hline Neurological symptoms & $0(0.0)$ & $9(7.4)$ & $<0.01$ \\
\hline Encephalitis & $0(0.0)$ & $2(1.6)$ & 0.01 \\
\hline Hypoxemia & $0(0.0)$ & $12(9.8)$ & $<0.01$ \\
\hline Refractory pneumonia & $164(26.0)$ & $61(50.0)$ & $<0.01$ \\
\hline Treatment in intensive care unit & $0(0.0)$ & $7(5.7)$ & $<0.01$ \\
\hline Death & $0(0.0)$ & $0(0.0)$ & - \\
\hline \multicolumn{4}{|l|}{ Laboratory indicators } \\
\hline $\mathrm{LDH}, \mathrm{U} / \mathrm{L}$ & $328.5(282.8-390.2)$ & $422.0(332.0-588.0)$ & $<0.01$ \\
\hline $\mathrm{IL}-2 \mathrm{R}, \mathrm{U} / \mathrm{mL}$ & $961.5(711.0-1274.5)$ & $1371.5(972.5-1985.2)$ & $<0.01$ \\
\hline CRP, mg/L & $11.0(4.0-22.0)$ & $18.0(8.0-39.5)$ & $<0.01$ \\
\hline \multicolumn{4}{|l|}{ Clinical outcomes } \\
\hline Duration of fever after admission, days & $1.0(0.0-3.0)$ & $3.0(2.0-4.0)$ & $<0.01$ \\
\hline Total fever duration, days & $8.0(6.0-10.0)$ & $9.0(7.0-12.0)$ & $<0.01$ \\
\hline Length of hospital stay, days & $6.0(5.0-8.0)$ & $9.0(7.0-12.0)$ & $<0.01$ \\
\hline
\end{tabular}

LDH, lactate dehydrogenase; IL-2R, interlukin-2 receptor; CRP, C-reactive protein.

Male, rash, neurological symptoms, encephalitis, hypoxemia, refractory pneumonia, treatment in intensive care unit, and death are presented as $\mathrm{n}(\%)$; the rest of the variables are indicated as median (25th-75th percentiles).

Table 2. Association of computed tomography features with severe Mycoplasma pneumoniae pneumonia (SMPP) $(n=752)$. 


\begin{tabular}{|c|c|c|c|c|c|c|}
\hline CT Characteristics & $\begin{array}{l}\text { Non-SMPP } \\
(n=630)\end{array}$ & $\begin{array}{l}\text { SMPP } \\
(n= \\
122)\end{array}$ & OR $(95 \% \mathrm{Cl})$ & $\begin{array}{l}P \text { - } \\
\text { value }\end{array}$ & $\begin{array}{l}\mathrm{OR}^{\mathrm{a}}(95 \% \\
\mathrm{Cl})\end{array}$ & $\begin{array}{l}P \text { - } \\
\text { value }^{a}\end{array}$ \\
\hline Consolidation & $557(88.4)$ & $\begin{array}{l}122 \\
(100.0)\end{array}$ & & & & \\
\hline \multicolumn{7}{|l|}{$\begin{array}{l}\text { Number of lobar } \\
\text { consolidation }\end{array}$} \\
\hline 0 and 1 lobe & 491 (77.9) & $\begin{array}{l}72 \\
(59.0)\end{array}$ & 1.0 & & 1.0 & \\
\hline 2 lobes & $113(17.9)$ & $\begin{array}{l}32 \\
(26.2)\end{array}$ & $\begin{array}{l}1.9(1.2 \\
3.1)\end{array}$ & 0.01 & $\begin{array}{l}2.0(1.3 \\
3.2)\end{array}$ & $<0.01$ \\
\hline 3 lobes & $22(3.5)$ & $\begin{array}{l}13 \\
(10.7)\end{array}$ & $\begin{array}{l}4.0(1.9 \\
8.4)\end{array}$ & $\begin{array}{l}<.01 \\
0.01\end{array}$ & $\begin{array}{l}4.1(2.0 \\
8.5)\end{array}$ & $<0.01$ \\
\hline 4 lobes & $4(0.6)$ & $5(4.1)$ & $\begin{array}{l}8.5(2.2 \\
32.5)\end{array}$ & $\begin{array}{l}< \\
0.01\end{array}$ & $\begin{array}{l}8.5(2.2 \\
32.6)\end{array}$ & $<0.01$ \\
\hline \multicolumn{7}{|l|}{$\begin{array}{l}\text { Location of } \\
\text { consolidation }\end{array}$} \\
\hline Upper lobe, right lung & 109 (17.3) & $\begin{array}{l}34 \\
(27.9)\end{array}$ & $\begin{array}{l}1.8(1.2, \\
2.9)\end{array}$ & 0.01 & $\begin{array}{l}1.9(1.2, \\
2.9)\end{array}$ & 0.01 \\
\hline Middle lobe, right lung & $170(27.0)$ & $\begin{array}{l}47 \\
(38.5)\end{array}$ & $\begin{array}{l}1.7(1.1 \\
2.5)\end{array}$ & 0.01 & $\begin{array}{l}1.8(1.2 \\
2.7)\end{array}$ & 0.01 \\
\hline Lower lobe, right lung & $156(24.8)$ & $\begin{array}{l}40 \\
(32.8)\end{array}$ & $\begin{array}{l}1.5(1.0 \\
2.3)\end{array}$ & 0.07 & $\begin{array}{l}1.4(0.9 \\
2.1)\end{array}$ & 0.13 \\
\hline Upper lobe, left lung & $144(22.9)$ & $\begin{array}{l}30 \\
(24.6)\end{array}$ & $\begin{array}{l}1.1(0.7 \\
1.7)\end{array}$ & 0.68 & $\begin{array}{l}1.1(0.7, \\
1.7)\end{array}$ & 0.68 \\
\hline Lower lobe, left lung & $147(23.3)$ & $\begin{array}{l}45 \\
(36.9)\end{array}$ & $\begin{array}{l}1.9(1.3 \\
2.9)\end{array}$ & $\begin{array}{l}< \\
0.01\end{array}$ & $\begin{array}{l}1.9(1.3 \\
2.9)\end{array}$ & $<0.01$ \\
\hline $\begin{array}{l}\text { Consolidation without air } \\
\text { bronchogram }\end{array}$ & $54(9.7)$ & $\begin{array}{l}35 \\
(28.7)\end{array}$ & $\begin{array}{l}3.7(2.3 \\
6.1)\end{array}$ & $<.01$ & $\begin{array}{l}3.7(2.3 \\
6.0)\end{array}$ & $<0.01$ \\
\hline Bilateral pneumonia & $339(53.8)$ & $\begin{array}{l}74 \\
(60.7)\end{array}$ & $\begin{array}{l}1.3(0.9 \\
2.0)\end{array}$ & 0.17 & $\begin{array}{l}1.4(0.9 \\
2.1)\end{array}$ & 0.11 \\
\hline Pleural effusion & $15(2.4)$ & $\begin{array}{l}104 \\
(85.2)\end{array}$ & $\begin{array}{l}236.9 \\
(115.8, \\
484.7)\end{array}$ & $\begin{array}{l}<.01 \\
0.01\end{array}$ & $\begin{array}{l}245.2 \\
(117.9, \\
510.1)\end{array}$ & $<0.01$ \\
\hline Atelectasis & $45(7.1)$ & $\begin{array}{l}28 \\
(23.0)\end{array}$ & $\begin{array}{l}3.9(2.3 \\
6.5)\end{array}$ & $\begin{array}{l}< \\
0.01\end{array}$ & $\begin{array}{l}3.9(2.3 \\
6.6)\end{array}$ & $<0.01$ \\
\hline Lymphadenopathy & $226(35.9)$ & $\begin{array}{l}59 \\
(48.4)\end{array}$ & $\begin{array}{l}1.7(1.1 \\
2.5)\end{array}$ & 0.01 & $\begin{array}{l}1.6(1.1 \\
2.4)\end{array}$ & 0.01 \\
\hline Bronchial wall thickening & $588(93.3)$ & 113 & $0.9(0.4$ & 0.78 & $0.9(0.4$ & 0.85 \\
\hline
\end{tabular}




\begin{tabular}{|c|c|c|c|c|c|c|}
\hline & & (92.6) & 1.9) & & 2.0) & \\
\hline Nodules & $313(49.7)$ & $\begin{array}{l}73 \\
(59.8)\end{array}$ & $\begin{array}{l}1.5(1.0 \\
2.2)\end{array}$ & 0.04 & $\begin{array}{l}1.5(1.0, \\
2.2)\end{array}$ & 0.06 \\
\hline Ground-glass attenuation & $478(75.9)$ & $\begin{array}{l}83 \\
(68.0)\end{array}$ & $\begin{array}{l}0.7(0.4 \\
1.0)\end{array}$ & 0.07 & $\begin{array}{l}0.7(0.4 \\
1.0)\end{array}$ & 0.08 \\
\hline $\begin{array}{l}\text { Interstitial reticulation } \\
\text { opacities }\end{array}$ & $193(30.6)$ & $\begin{array}{l}47 \\
(38.5)\end{array}$ & $\begin{array}{l}1.4(0.9, \\
2.1)\end{array}$ & 0.09 & $\begin{array}{l}1.4(0.9 \\
2.1)\end{array}$ & 0.10 \\
\hline
\end{tabular}

OR and $95 \% \mathrm{Cl}$ intervals are presented to show the association between patients with CT characteristics and SMPP, as compared with patients without such CT characteristics.

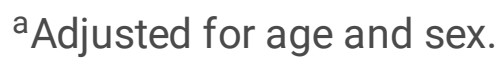

$\mathrm{CT}$, computed tomography; SMPP, severe Mycoplasma pneumoniae pneumonia; OR, Odd Ratio; Cl: confidence interval.

Table 3. Clinical outcome of patients with MPP stratified by the number of lobar consolidation based-CT.

\begin{tabular}{|c|c|c|c|c|c|c|}
\hline \multirow[t]{2}{*}{$\begin{array}{l}\text { Number of lobar } \\
\text { consolidation }\end{array}$} & \multicolumn{3}{|c|}{$\begin{array}{l}\text { Endpoint 1: Time to Hospital } \\
\text { Discharge (Days) }\end{array}$} & \multicolumn{3}{|c|}{$\begin{array}{l}\text { Endpoint 2: Time to Defervescence } \\
\text { (Days) }\end{array}$} \\
\hline & $\mathrm{n}(\%)$ & $\begin{array}{l}\text { Hazard Ratio }{ }^{a} \\
(95 \% \mathrm{Cl})\end{array}$ & $\begin{array}{l}P- \\
\text { value }\end{array}$ & n (\%) & $\begin{array}{l}\text { Hazard Ratio }{ }^{\mathrm{a}} \\
(95 \% \mathrm{Cl})\end{array}$ & $\begin{array}{l}P \text { - } \\
\text { value }\end{array}$ \\
\hline $\begin{array}{l}0 \text { lobe of } \\
\text { consolidation }\end{array}$ & $\begin{array}{l}73 \\
(9.7)\end{array}$ & Ref & - & $\begin{array}{l}38 \\
(7.2)\end{array}$ & Ref & - \\
\hline $\begin{array}{l}1 \text { lobe of } \\
\text { consolidation }\end{array}$ & $\begin{array}{l}490 \\
(65.2)\end{array}$ & $0.42(0.33,0.54)$ & $\begin{array}{l}< \\
0.01\end{array}$ & $\begin{array}{l}346 \\
(65.8)\end{array}$ & $0.64(0.46,0.89)$ & 0.01 \\
\hline $\begin{array}{l}2 \text { lobes of } \\
\text { consolidation }\end{array}$ & $\begin{array}{l}145 \\
(19.3)\end{array}$ & $0.36(0.27,0.48)$ & $<.01$ & $\begin{array}{l}107 \\
(20.3)\end{array}$ & $0.57(0.39,0.82)$ & $<.01$ \\
\hline $\begin{array}{l}3 \text { lobes of } \\
\text { consolidation }\end{array}$ & $\begin{array}{l}35 \\
(4.7)\end{array}$ & $0.31(0.21,0.47)$ & $\dot{0}_{0.01}$ & $\begin{array}{l}28 \\
(5.3)\end{array}$ & $0.52(0.32,0.84)$ & 0.01 \\
\hline $\begin{array}{l}4 \text { lobes of } \\
\text { consolidation }\end{array}$ & $9(1.2)$ & $0.17(0.08,0.33)$ & $\begin{array}{l}<.01 \\
0.01\end{array}$ & $7(1.3)$ & $0.28(0.12,0.62)$ & $\begin{array}{l}<.01 \\
0.01\end{array}$ \\
\hline
\end{tabular}

MPP: Mycoplasma pneumoniae pneumonia; CT, computed tomography;

Data are presented as No. (\%). OR = odds ratio; $\mathrm{Cl}$, confidence interval. All OR calculations were made using $\leq 75^{\text {th }}$-percentile value data as a reference.

a Adjusted for age, sex.

Table 4. Cost comparison in individuals stratified by number of lobar consolidation. 


\begin{tabular}{|c|c|c|c|c|c|c|}
\hline $\begin{array}{l}\text { Number of } \\
\text { lobar } \\
\text { consolidation }\end{array}$ & $\begin{array}{l}0 \\
N=73\end{array}$ & $\begin{array}{l}1 \\
N=490\end{array}$ & $\begin{array}{l}2 \\
N=145\end{array}$ & $\begin{array}{l}3 \\
N=35\end{array}$ & $\begin{array}{l}4 \\
N=9\end{array}$ & $\begin{array}{l}\mathrm{P} \text { - } \\
\text { value }\end{array}$ \\
\hline $\begin{array}{l}\text { Hospital } \\
\text { charges, \$ }\end{array}$ & $\begin{array}{l}1022.6 \\
(846.7- \\
1133.3)\end{array}$ & $\begin{array}{l}1535.8 \\
(1110.5- \\
1964.5)\end{array}$ & $\begin{array}{l}1675.5 \\
(1135.9- \\
2138.1)\end{array}$ & $\begin{array}{l}1552.6 \\
(1232.0- \\
2303.5)\end{array}$ & $\begin{array}{l}2513.4 \\
(1788.2- \\
3097.2)\end{array}$ & $<0.001$ \\
\hline $\begin{array}{l}\text { Laboratory } \\
\text { tests, } \$\end{array}$ & $\begin{array}{l}414.3 \\
(333.4- \\
542.5)\end{array}$ & $\begin{array}{l}627(396.5- \\
816.6)\end{array}$ & $\begin{array}{l}611(400.9- \\
816.6)\end{array}$ & $\begin{array}{l}609.8 \\
(409.0- \\
830.0)\end{array}$ & $\begin{array}{l}834.6 \\
\text { (518.8- } \\
951.7)\end{array}$ & $<0.001$ \\
\hline $\begin{array}{l}\text { Imaging costs, } \\
\$\end{array}$ & $\begin{array}{l}67.7(38.5- \\
84.2)\end{array}$ & $\begin{array}{l}107.7 \\
(64.6- \\
128.3)\end{array}$ & $\begin{array}{l}104.9 \\
(66.2- \\
127.8)\end{array}$ & $\begin{array}{l}117.5(73.5- \\
128.3)\end{array}$ & $\begin{array}{l}128.3 \\
(105.4-151)\end{array}$ & $<0.001$ \\
\hline Medication, \$ & $\begin{array}{l}206.2 \\
(151- \\
282.4)\end{array}$ & $\begin{array}{l}345.5 \\
(238.2- \\
488.3)\end{array}$ & $\begin{array}{l}389.4 \\
(259.2- \\
545.7)\end{array}$ & $\begin{array}{l}413.9 \\
(267.5- \\
648.1)\end{array}$ & $\begin{array}{l}554.7 \\
(353.4- \\
1143.1)\end{array}$ & $<0.001$ \\
\hline
\end{tabular}

Data are presented as median (25th-75th percentile).

Figures 
5112 hospitalized children with community acquired pneumonia (2016.02-2019.07)

917 patients confirmed with Mycoplasma pneumoniae pneumonia

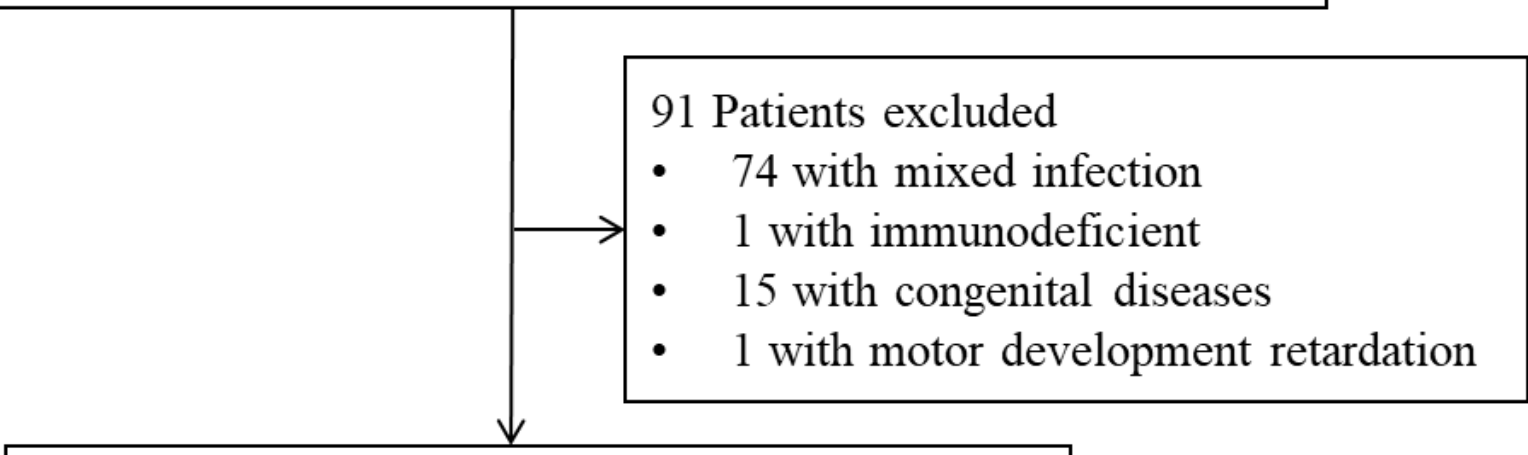

826 patients received chest X-ray examination

752 patients received low-dose CT examination due to

- suggesting serious complications by $\mathrm{CX}$

- high suspicion of pneumonia and CX fail to show signs of pneumonia

- CX is difficult to determine the location and extent of pneumonia

- excluding other diseases

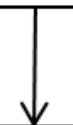

752 patients included

Figure 1

Flow diagram for generation of the study population. 


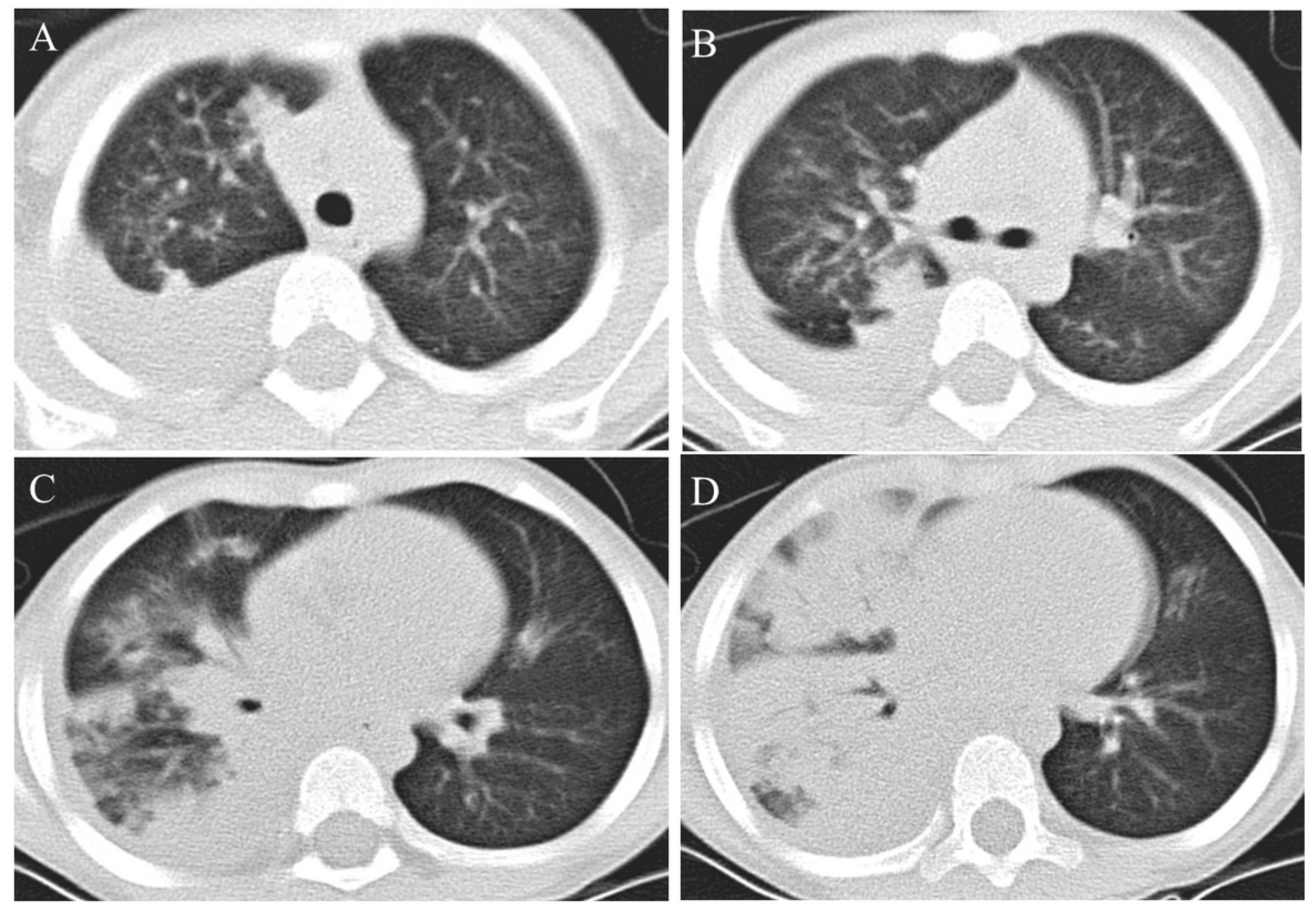

Figure 2

Various chest CT features in patients with Mycoplasma pneumoniae pneumonia, including nodules (A), bronchial wall thickening (B), ground-glass attenuation (C), lobar consolidation (D) and pleural effusion (A-D). 


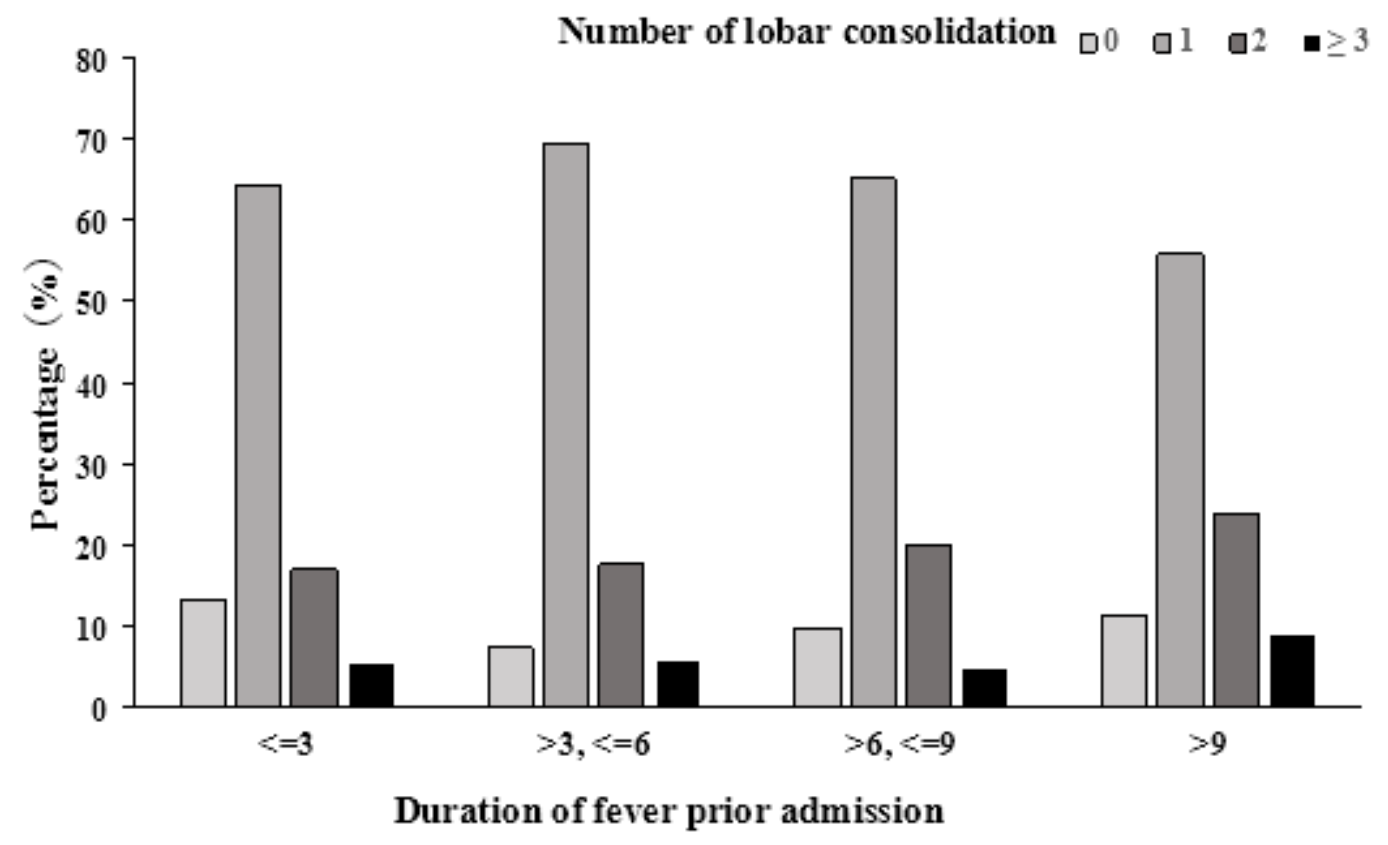

Figure 3

The proportions of lobar consolidation in children with Mycoplasma pneumoniae pneumonia stratified by fever duration before admission $(n=752)$.
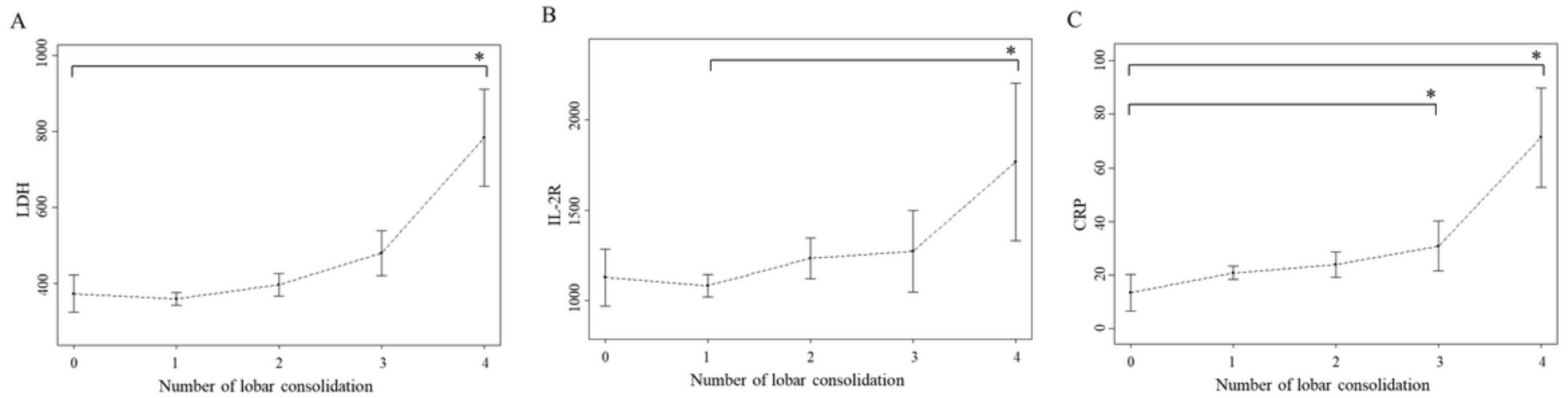

Figure 4

Mean concentrations of serum lactate dehydrogenase (LDH) (A), interleukin-2R (IL-2 R) (B), and C-reactive protein (CRP) (C) in patients with lobar consolidation from 0 to 4 lobes. 
A Number of lobar consolidation $-0-1-{ }_{2}-{ }_{3}-{ }_{4}$

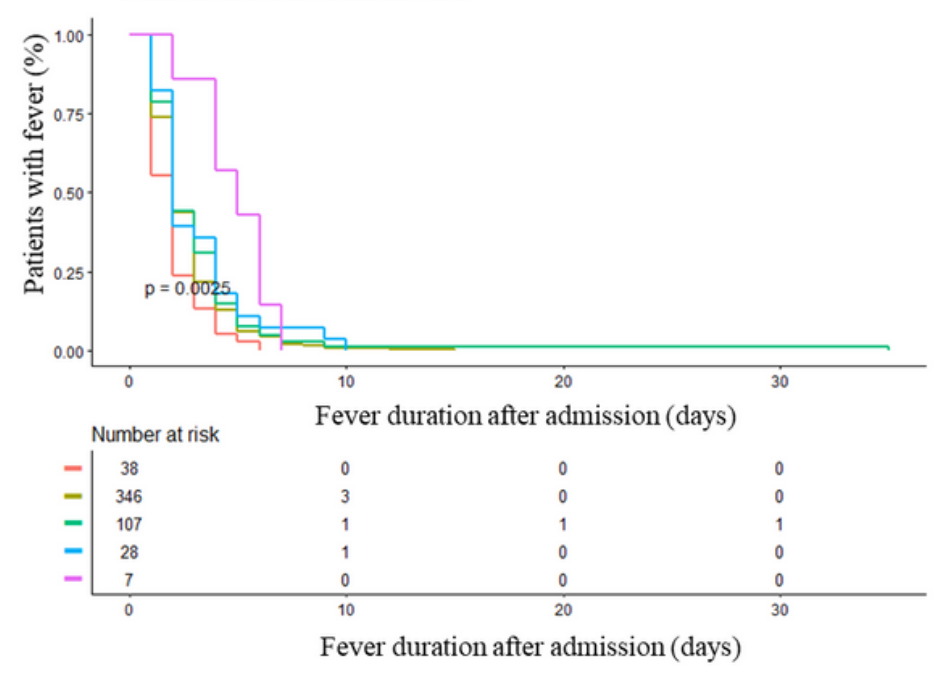

B Number of lobar consolidation $-0-1-2_{3}-4$

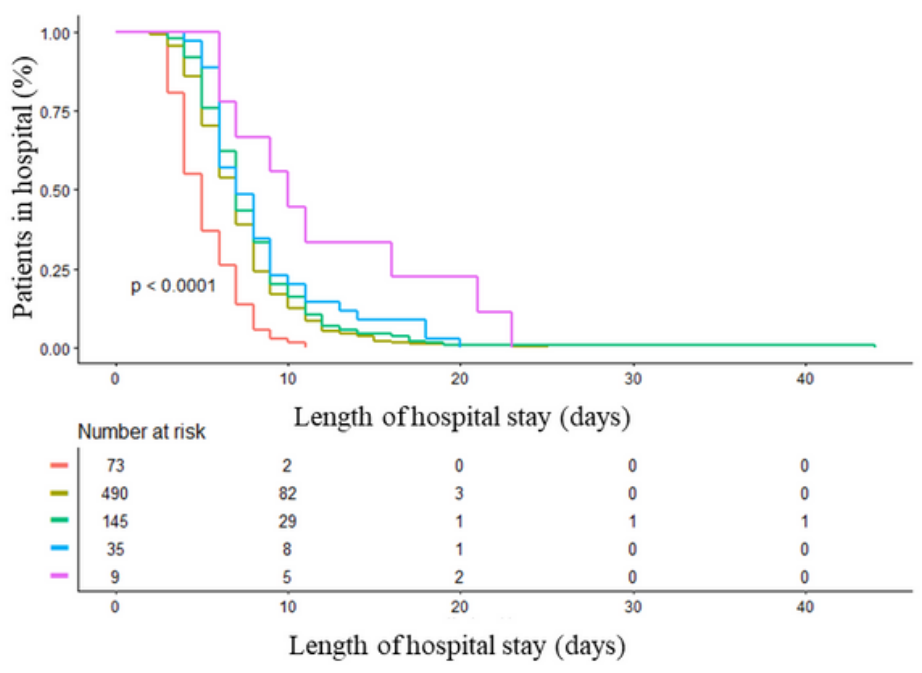

\section{Figure 5}

Kaplan-Meier analysis of fever duration after admission (A) and length of hospital stay(B) according to the number of lobar consolidation. 